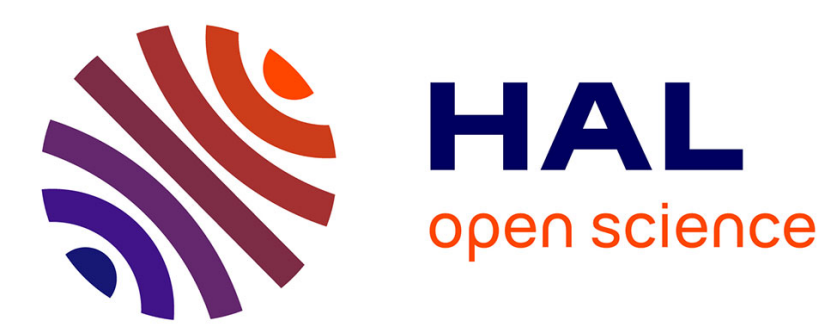

\title{
A Persona-based Semantics for Slurs
}

Heather Burnett

\section{To cite this version:}

Heather Burnett. A Persona-based Semantics for Slurs. Grazer Philosophische Studien - Internationale Zeitschrift für Analytische Philosophie, 2020, 97 (1), pp.31-62. 10.1163/18756735-09701004 . hal03099577

\section{HAL Id: hal-03099577 https://hal.science/hal-03099577}

Submitted on 6 Jan 2021

HAL is a multi-disciplinary open access archive for the deposit and dissemination of scientific research documents, whether they are published or not. The documents may come from teaching and research institutions in France or abroad, or from public or private research centers.
L'archive ouverte pluridisciplinaire HAL, est destinée au dépôt et à la diffusion de documents scientifiques de niveau recherche, publiés ou non, émanant des établissements d'enseignement et de recherche français ou étrangers, des laboratoires publics ou privés. 


\title{
A Persona-Based Semantics for Slurs*
}

\author{
Heather Burnett \\ Laboratoire de Linguistique Formelle \\ CNRS-Université Paris-Diderot
}

\begin{abstract}
This paper presents a new style of semantic analysis for slurs: linguistic expressions used to denigrate individuals based on some aspects of their identity. As an illustration, I will focus on one slur in particular: dyke, which is generally considered to be a derogatory term for lesbians. I argue that current research on these terms is limited in (at least) two ways: firstly, I argue not enough attention has been paid to the use of dyke by members of the target group, who can often use it in an non-insulting manner; secondly, I argue not enough attention has been paid to the use of the "neutral" form, lesbian, which is generally treated as having a simple, clear meaning, such as "engage[s] in same-sex sex" (Jeshion, 2013a, 312). Following McConnell-Ginet (2002), I argue that the semantics of lesbian is actually quite complex, and that taking into account all the uses of both dyke and lesbian requires a new semantics and pragmatics for both terms. More specifically, I propose that dyke and lesbian are associated with different sets of personae: abstract identities or stereotypes. Dyke is associated with an anti-mainstream persona, which the vast majority of speakers views negatively; whereas, lesbian is associated with a mainstream persona, which many speakers view favourably. I propose that the semantic puzzles associated with dyke and lesbian can be resolved through the combination of a theory of these personae and a theory of how listeners' beliefs about their interlocutors' ideologies affect utterance interpretation.
\end{abstract}

\section{Introduction}

This paper presents a new style of semantic analysis for slurs: linguistic expressions used to denigrate individuals based on some aspects of their identity. Although slurs have a

\footnotetext{
*I thank audiences at the SOPHA in Louvain-la-Neuve, ZAS Berlin and Universität Potsdam, Olivier Bonami, Igor Douven, Paul Égré, Sally McConnell-Ginet, Eliot Michaelson, Uli Sauerland and Stephanie Solt for helpful comments on this project. Of course all errors and oversights are my own. This work is partially supported by public grants overseen by the French National Research Agency (ANR) (references: ANR-10-LABX-0083 and ANR-14-CE30-0010).
} 
long history of study in formal semantics and analytic philosophy, their identifying properties and characterizing patterns of use and interpretation remain very controversial 1 , These controversies range from how to solve the intricate puzzles that slurs raise for current formal semantic theories, to more general questions concerning how the use of these expressions harms their target both directly, through feelings of hurt and offense, and indirectly, through the role that they play in supporting and inciting discrimination and violence (see Tirrell (2012)). Rather than proposing a unified theory of this very diverse class of powerful words, as an illustration, I will provide an in-depth study of one slur in particular: dyke, which is generally considered to be a derogatory term for lesbians. An example of a derogatory use of dyke is shown in the first pane of Figure 1, from the 2008 preface to Allison Bechdel's long running comic strip Dykes to watch out for. In this comic, we see two women with short hair going into a concert and a man standing on the street calls out "Fuckin' dykes." at them insultingly.
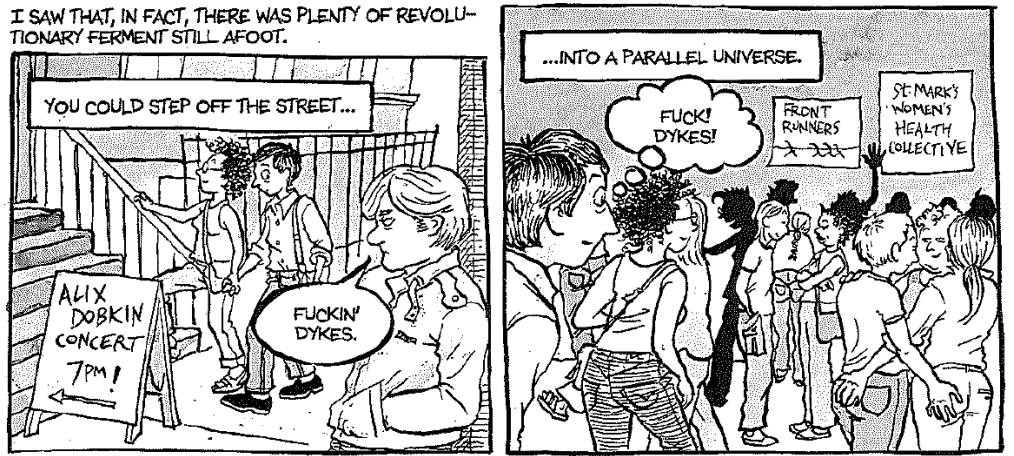

Figure 1 - From the preface to The Essential Dykes to Watch Out For (Bechdel, 2008)

Dyke and lesbian constitute a classic example of a pair consisting of a slur and its socalled "neutral" counterpart, having been discussed in many works in formal semantics and philosophy by Tirrell (1999); Camp (2013); Jeshion (2013a); Cepollaro (2017), among others. Despite this attention, I argue that current research on these terms is limited in (at least) two ways: firstly, I argue that not enough attention has been paid to the use of the slur $(d y k e)$ by members of the target group. Like many other slurs, members of the target group can often use dyke in a non-insulting manner, as shown in the second pane in Figure 1, which contrasts with the insulting use in the previous pane. Secondly, I argue that not enough attention has been paid to the use of the "neutral" form (lesbian), which is generally treated as having a simple, clear meaning, often based on a single contextindependent property such as (for example) "engage[s] in same-sex sex" (Jeshion, 2013a, 312). Following McConnell-Ginet (2002), I argue that the semantics of lesbian is actually

${ }^{1}$ This is easily seen from $\begin{aligned} & \text { recent intense discussions on } \\ & \text { voted to plogs de- }\end{aligned}$
derogatory-language-philosophy-journal-hostility-discussion/) and linguistics (such as
http://languagelog.ldc.upenn.edu/nll/?p=33789)


quite complex, and that taking into account all the uses of both dyke and lesbian requires a new semantics and pragmatics for both terms.

With this in mind, I present a persona-based semantics for dyke and lesbian. In contrast to the vast majority of the literature on the topic, I argue that, at least for some speakers, the two terms are not truth conditionally equivalent. More specifically, I propose that $d y k e$ and lesbian are associated with different sets of personae, which are abstract identities or stereotypes. Dyke is associated with an anti-mainstream persona, which the vast majority of speakers views negatively. On the other hand, for many speakers, lesbian is associated with a mainstream persona, which many speakers view favourably. In this context, the term mainstream refers to the property of engaging with and being supported by the main social institutions such as the education system, the family, the immigration and legal systems etc. I propose that the semantic puzzles associated with dyke and lesbian can be resolved through the combination of a theory of these personae and a theory of how listeners' beliefs about their interlocutors' ideologies affect utterance interpretation. Additionally, I propose that the aspect of the meaning of dyke that makes it particularly useful to those wanting to harm its target lies in its function to encourage those who hear it to envision the target as being located outside mainstream institutions, which then leaves them particularly vulnerable to oppression and violence from actors outside and inside those institutions. In order to show explicitly how dyke changes listeners' beliefs about its referent, I use Gärdenfors (2000, 2014)'s Conceptual Spaces framework to formalize speaker/listener ideologies, and give an analysis of the meanings of the slur and the 'neutral' term within this framework.

The paper is laid out as follows: In section 2, I outline some of the puzzles that the use and interpretation of slurs pose for their analysis within classic formal semantic frameworks. I show how dyke gives rise to all of these puzzles, but argue that many current approaches have difficulty accounting for the patterns observed with this particular slur. In section 3 , I present new data associated with the use of dyke by in group members, and I argue that notions such as personae or stereotypes are crucial to understanding these observations. I then provide a detailed description of the personae that, I argue, form the basis of the meaning of dyke and lesbian. Building on previous work in sociolinguistics, I argue that the source of offensive uses of the slur dyke is its relationship to an anti-mainstream persona; whereas, for many speakers, lesbian is associated with at least one mainstream persona, which allows for non-slur uses of this term. Finally in section 4 , I present a formal framework for capturing the link between ideological structure and language use/interpretation: Gärdenfors (2000, 2014)'s Conceptual Spaces. I set my analysis of the meaning of dyke and lesbian in this framework, and I show how it solves the puzzles described in section 2 . Section 5 concludes with a discussion of the implications of a persona-based semantics of slurs in the material aspects of discrimination and oppression. 


\section{The puzzles of slurs for formal semantics}

One of the reasons that slurs have received such attention in formal semantics and analytic philosophy of language is that they display a number of patterns that are challenging to analyze within classical logical approaches to meaning. The first such puzzle is the observation that the use of a sentence containing a slur, like (1-a), is usually taken to indicate that the speaker holds some derogatory attitude while the use of (1-b) is usually not (Kaplan, 1999; Potts, 2007; McCready, 2010; Hedger, 2012, a.o.).
a. Sarah is a dyke.
b. Sarah is a lesbian.

The test that I will use in this paper for the presence of a derogatory attitude is, what I call, the Dude, not cool! test ${ }^{2}$. More specifically, we will say that an utterance communicates a derogatory attitude to a listener just in case the listener feels like saying Dude, not cool! after hearing the utterance. Applying this test to (2-a) and (2-b) (based on my own intuitions as listener), we can observe the following contrast: if someone who is not a lesbian tells me (a lesbian) (2-a), my first reaction is to think: Dude, not cool!; however, if someone tells me (2-b), then I do not have this reaction. So the puzzle is: how exactly does $\boldsymbol{d} \boldsymbol{y} \boldsymbol{k} \boldsymbol{e}$ communicate this derogatory attitude?

$$
\begin{aligned}
& \text { a. Sarah is a dyke. } \\
& \text { b. Sarah is a lesbian. }
\end{aligned}
$$

Dude, not cool!

Ok, that's nice...

The second puzzle associated with the use of slurs is the observation that these terms can be offensive even when the speaker does not intend to be so (Hom, 2008; Anderson and Lepore, 2013a; Bolinger, 2017, among others). I will illustrate this puzzle with a naturally occurring example: I used to live in the south of France and during this time I attended a dinner party that was given by one of my American friends there. One of the other guests was another friend, a very friendly gay man, who was on vacation in Toulouse from San Francisco. At one point, we were talking about relationships and he asked me if I had a partner. I said no and that the lesbian dating scene in the south France wasn't excellent, to which he said (3-a). This person was clearly not trying to be offensive; indeed he was trying to be friendly. Nevertheless, my first reaction was Dude, not cool!. This is the offensive autonymy puzzle: How does dyke communicate this derogatory attitude, even in absence of a speaker's derogatory intentions?

\section{a. Well-meaning gay man visiting from San Francisco: Aren't there any}

\footnotetext{
${ }^{2}$ This test is on analogy with von Fintel (2004)'s Hey, wait a minute. . test for presuppositions. Note that in American English, dude is a gender neutral expression (see Kiesling, 2004); therefore, this test does not presuppose anything about the gender of the speaker.
} 
dyke bars in Toulouse?

b. The author: I beg your pardon? Dude, not cool!

The final frequently discussed puzzle associated with the use of slurs by 'out group' members is the observation that the derogatory attitude communicated in unembedded assertions appears to project out of all, or almost all, semantic environments Kaplan, 1999, Kratzer, 1999; Potts, 2007; Schlenker, 2007; Sauerland, 2007; Camp, 2013, among many others). For example, out group members using dyke in a negative sentence (4-b), in the antecedent of a conditional (5-a) or in a question (5-b) is still just as not cool as in the simple affirmation (4-a) This is the unpluggability puzzle: how does dyke communicate this derogatory attitude, even in the presence of other semantic elements that block other kinds of content from projecting?

a. Sarah is a dyke.

Dude, not cool!

b. Sarah is not a dyke.

Dude, not cool!

a. If Sarah is a dyke, then she'll know when the Pride parade is. Dude, not cool!

b. Is Sarah a dyke?

Dude, not cool!

In formal semantics, the most common line of analysis, called expressivism, is to propose that the derogatory attitude is somehow encoded into the meaning of the slur (Schlenker, 2003, 2007; Potts, 2005, 2007, 2012; Sauerland, 2007; McCready, 2010; Jeshion, 2013a,b; Gutzmann, 2015, among many others). To give a couple examples: Jeshion (2013a) proposes the analysis in (6), where the attitude encoded in the meaning of the slur is contempt. Schlenker (2007) analyses honkey as having a presupposition that the speaker believes that white people are despicable, and McCready (2010) likewise encodes a belief that Germans are bad into the expressive content of her analysis of kraut (8),

(6) "For a group slurring term S with a neutral counterpart NC that references a group

\footnotetext{
${ }^{3}$ It has been observed that the derogatory attitude of some slurs and swear words may be 'pluggable' in some more complicated semantic contexts, such as indirect discourse (Kratzer, 1999, Schlenker, 2003, 2007, among others). My intuitions about these cases, modified with dyke, are not very strong, although it does seem to me that the derogatory attitude continues to project even in environments such as (i) and (7), which block the attitude with other expressions. Additional experimental or corpus work on these cases is desirable.
}

(i) My father screamed that he would never allow me to marry that dyke Sarah. (modified from Kratzer (1999) with bastard) Dude, not cool!

(ii) I am not prejudiced against lesbians. But John, who is, thinks/claims that you are the biggest dyke he knows.

(modified from Schlenker (2007) with honkey) Dude, not cool! 
$\mathrm{G}, \mathrm{S}$ is used to express contempt for members of $\mathrm{G}$ on account of their being in $\mathrm{G}$ or on account of their possessing a G-defining property g." (Jeshion, 2013a, 308)

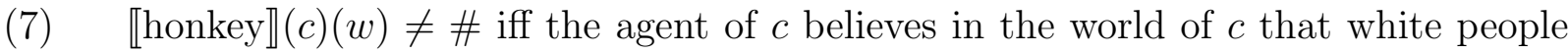
are despicable. If $\neq \#$, , «honky $\rrbracket(c)(w)=\llbracket$ white $\rrbracket(c)(w) . \quad$ Schlenker, 2007, 237)

$$
\llbracket \operatorname{kraut} \rrbracket=\lambda x . \operatorname{German}(x) \diamond \operatorname{bad}\left({ }^{\cap} \text { German }\right):\langle e, t\rangle^{a} \times t^{s} \quad(\text { McCready, 2010, 21) }
$$

For expressivist analyses, there is no mystery where the derogatory attitude comes from: it's part of the lexical meaning of the slur. Having the derogatory attitude as part of the meaning of the slur also predicts its offensive autonymy: even if you hold no particular prejudice against a group, if you use a word that has contempt as part of its meaning, you can't be upset if others understand you as expressing your contempt when you use it. Expressivist analyses account for projection properties through how the attitude is encoded into the slur: in some approaches, it is part of expressive content, a separate domain of meaning which cannot interact with regular truth-conditional meaning, as in (8) (see also Potts, 2007; Richard, 2008; McCready, 2010; Gutzmann, 2015, among others), or it takes the shape of an indexical presupposition which must almost always be resolved to the speaker in the context, as in (7) (Schlenker, 2007; Sauerland, 2007). In both styles of analysis, the attitude is predicted to be almost always unpluggable.

Expressivist analyses have been very successful for analyzing the properties of slurs when they are used to denigrate individuals who are not part of the target group. However, it has been observed many times ${ }^{4}$ that encoding a derogatory attitude into the meaning of a slur creates problems when we consider non-derogatory uses by 'in group' members, such as the use in the second pane in Figure 1. This is the appropriation puzzle: How can the derogatory attitude disappear in the mouths of members of the target group?

When it comes to non-derogatory uses of slurs by in group members, it is important to distinguish a couple of different cases. Firstly, there are echoic non-derogatory uses, which have been studied by Bianchi (2014), in which "in-groups echo derogatory uses in ways and contexts that make manifest the dissociation from the offensive contents" (Bianchi, 2014, 36). An example of an echoic use is shown in Figure 2. In this comic, Ginger is pushing Clarice in a wheelchair down the steps of the university, which a distinguished looking professor walks by. Clearly imitating what elitist members of the university community might say/think, Clarice jokes that if the university installed ramps then it would be overrun by "black commie dykes in wheelchairs".

However, echoic uses only begin to scratch the surface of the variety of meaningful nonderogatory uses of slurs by 'in group' members. For example, consider the panes in Figure 3 , which depict Mo, Ginger and Lois (three lesbians in their late 20s) having coffee together. Mo reflects on how she and her friends used to be subversives and radicals, but now

\footnotetext{
${ }^{4}$ See the discussion in (Hornsby, 2001, Croom, 2011, 2013; Anderson and Lepore, 2013a; Anderson, 2018; Ritchie, 2017; Bianchi, 2014, among others)
} 


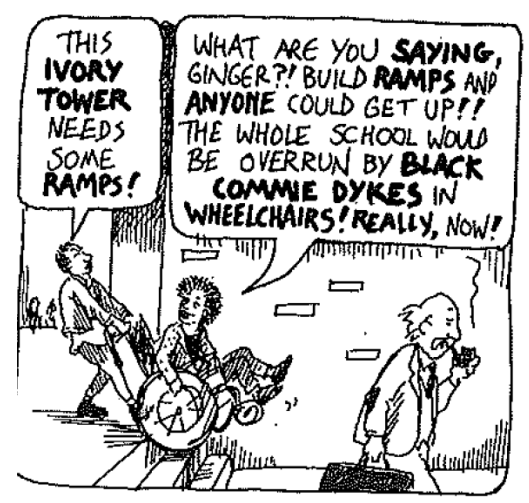

Figure 2 - Dykes to Watch Out For \#31 (1988), (Bechdel, 2008, 27)

have mellowed with age such that the young women group them together with insurance salesmen. In Figure 3, Mo is clearly not echoing the words of some imagined bigot and the attitude that is communicated here is admiration rather than contempt.
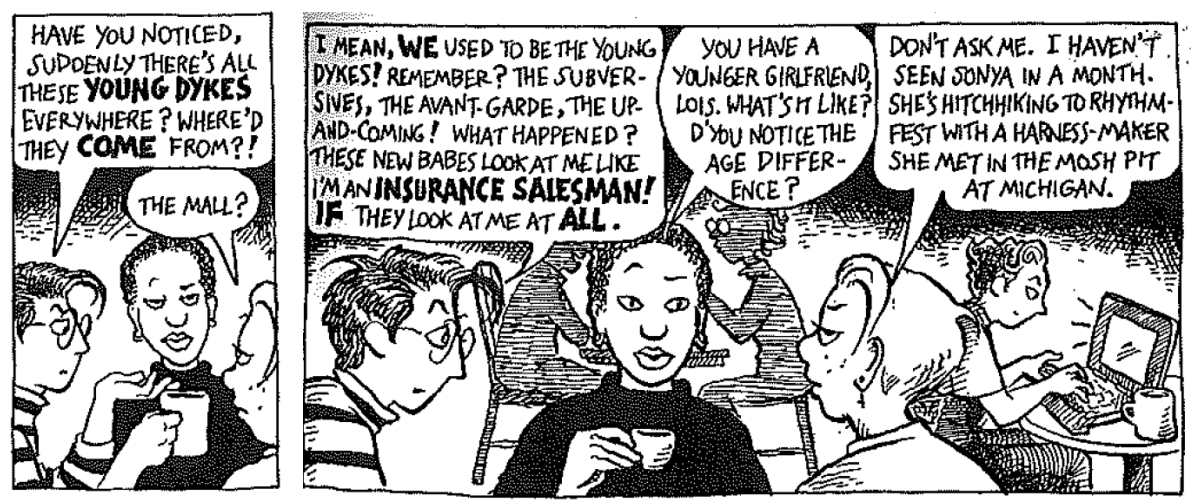

Figure 3 - Dykes to Watch Out For \#197 (1994) (Bechdel, 2008, 129)

The most common response to such examples is to propose that non-negative uses of a slur are actually instances of a distinct homophonous predicate that has been created by an 'appropriation' process, and whose meaning does not encode a derogatory attitude. For example, (Richard, 2008, 16) says that "in appropriation there [is] a change in meaning". Likewise, (Jeshion, 2013a, 326) gives an analysis of appropriated queer saying,

It is plausible that the term acquired a new meaning via the process of appropriation. On this analysis, queer became semantically ambiguous upon appropriation. Initially, it was non-ambiguous, its only linguistic standing as a slur, one whose derogating capacity can be accounted for semantically. Later, it came to have another conventional use, one that is non-pejorative.

However, as observed by (Anderson and Lepore, 2013a; Ritchie, 2017, among others), proposing that non-negative uses of slurs result from the creation of a separate predicate runs into another puzzle known as the appropriation worry: if there exists a separate 
non-derogatory predicate, then why can't 'out group' members use it? Observe that if (9) is said by a non-lesbian, the admirative attitude of Figure 3 disappears.

Have you noticed, suddenly there's all these young dykes everywhere?

Dude, not cool!

The appropriation worry therefore indicates that we would like a single analysis of $d y k e$ that accounts for its uses by both 'in group' and 'out group' members.

One such an analysis is Anderson and Lepore (2013a)b); Anderson (2018)'s deflationary theory. These authors propose that the derogatory attitude is not encoded into the meaning of the slur. Rather, slurs are derogatory because they are prohibited or taboo terms, and, as Anderson and Lepore (2013a) say (p.38), "when a word is prohibited, then whoever violates its prohibition risks offending those who respect it". The deflationary theory elegantly accounts for the derogatory attitude and offensive autonomy: the offensive attitude is created by taboo violation and violating a taboo is not dependent on an individuals' intentions. Likewise, since a slur's offense is completely pragmatic, the offense is predicted to be unpluggable. Furthermore, since the derogatory attitude is not encoded in the meaning of the slur, non-derogatory uses are predicted to be possible, which addresses the appropriation puzzle. Anderson (2018) also provides a solution to the appropriation worry through the observation that taboos and norms are different inside different speech communities/communities of practice. Focusing on the n-word and building on work by sociolinguists (Baugh, 1983, Smitherman, 2006), Anderson proposes (p.32) that "endearing or neutral uses of the [n-word] among African American speakers emerge from an illocutionary act of addressing, one that is available only to members of the relevant community of practice." This special illocutionary act allows utterances used by 'out group' members as insults to have the illocutionary force of expressions of solidarity and friendship, and suggests that " the tying of friendly interpretation to insider status in this case is not an isolated incident, but an instance of a much more widespread phenomenon."

Although Anderson's analysis for endearing uses of the n-word may be appropriate for this term, I argue that something else is going on with dyke. For one thing, the interpretations of non-negative dyke are very different from the endearing uses of the n-word. To see this, we can consider the use of lesbian vs dyke by the Lesbian Avengers, a lesbian direct action group formed in 1992 in New York. This association aimed to distinguish itself from other lesbian political groups by being "a group totally focused on high-impact street activism, not on talking" "5. In order to stress their "action over talking" nature, the group named its initial publication the Dyke Manifestd 6 , which begins as in (10).

Calling all lesbians

Wake up! Wake up! Wake up!

\footnotetext{
${ }^{5}$ Co-founder Ana Simo http://www.lesbianavengers.com/about/history.shtml

${ }^{6}$ Available at the Queen Zine Archive project: http://www.qzap.org/v5/gallery/main.php
} 
It's time to get out of the beds, out of the bars and into the streets

Time to seize the power of dyke love, dyke vision, dyke anger

dyke intelligence, dyke strategy

Time to organize and ignite. Time to get together and fight

We're invisible and it's not safe-not at home, or on the job, in the

streets or in the courts

Where are our lesbian leaders?

Although the manifesto clearly builds on the solidarity of its intended audience, the uses of dyke in (10) are far from friendly. The function of dyke in this text appears to be to increase the urgency and the gravity of the call to action. So, to apply the deflationary theory, an illocutionary act of incitation rather than addressing would have developed in lesbian-specific communities of practice and have become associated with dyke. The main problem with the idea of a special lesbian speech act is that it is at odds with essentially all previous work on lesbian language in sociolinguistics and linguistic anthropology, which denies that there are linguistic ways in which lesbian speech communities/communities of practice distinguish themselves from other "non-lesbian" communities (Stanley and Wolfe, 1980; Moonwomon-Baird, 1985; Queen, 1997; Cameron and Kulick, 2003; Koller, 2008, among others). For example, in her 1997 article I Don't Speak Spritch: Locating Lesbian Language, Robin Queen argues that "the nature of the speech community [...] is inadequate for accommodating the unique form of lesbian language" (Queen, 1997, 233) and proposes instead a 'contact-based' model, where 'lesbian language' is composed of features of stereotyped women's language (in the sense of Lakoff, 1973), stereotypical nonstandard varieties, often associated with working class urban males (Labov, 1972), stereotyped gay male language, and finally stereotyped lesbian language 7 (such as cursing and use of expressions like bite me and suck my dick). In other words, "by combining the stereotypes of non-lesbian communities with the stereotypes that lesbians hold about themselves, lesbians create an indexical relationship between language use and a lesbian "identity" (Queen, 1997, 239).

\section{Personae for dykes and lesbians}

In this section, I build on Queen's idea that something like stereotypes plays a role in 'lesbian language' and are crucial to understanding the meaning of both dyke and lesbian 8 . One way that this can be seen is through looking at the interpretation of gradable constructions containing these terms. Dyke is an English noun which can be subject to morphological adjective-formation processes such as $-y$ or -ish suffixation, creating the adjectives $d y k e-y$ and dyke-ish. A naturally occurring 'in group' use of dykey from Jones (2012)'s linguistic

\footnotetext{
${ }^{7}$ Where these stereotypes are not restricted to lesbians themselves, but are part of the broader culture.

${ }^{8}$ This idea that personae are involved in the meaning of $d y k e$ is also developed from an anthropological perspective by Jones (2012).
} 
ethnography of a lesbian hiking group in the UK is shown in (11), and an 'out group' use of dykeish is shown in (12), from a romance novel written by two men.

(11) S: Well yeah. She's the only one who looks vaguely like a dyke actually.

L: But you see everyone fancies her which suggests-

S: That she's the only dykey one.

Two members of the lesbian hiking group discussing Shane from the L Word (Jones, $2012,73)$

(12) She had really nice brown hair and that annoying East Coast accent, and had the body of a track star: very hard and toned, but not bulky or dyke-ish.

(James and Edwards, 2006, 69) Dude, not cool!

These adjectives indicate that their argument bears some non-trivial degree of closeness to a prototypical $d y k e$ or some idealization of dyke-ishness, and we can use a wide range of degree constructions to order individuals with respect to how close or far away from this ideal they are. For example, (13) shows an example of a comparative, from Taub (1999)'s study on sexuality and appearance, and (14) shows an example with too and enough from Ross (2009)'s study of the Burlesque scene in Vancouver.

(13) I have a dyke look that I assume when I want to fit in more with lesbian social settings, and I think I've been more careful about keeping my haircut very crisp and clean so I can look more dykey when I want to instead of letting it go longer and shaggier.

40 year old participant in (Taub, 1999, 31).

(14) She remembers being ostracized by club owners for being too dykey at the same time that she was shunned, as was Roxanne, by the women's community for not being dykey enough.

$\operatorname{Ross}(2009)$

One style of account which is already equipped to handle the gradability of dyke is the one based on stereotypes by ( $\mathrm{Hom}, 2008,2010)$. According to this approach, a (racist) slur means (Hom, 2008, 431):

Ought be subject to $p_{1}+\ldots+p_{n}$, because of being $d_{1}+\ldots+d_{n}$, all because of being $\mathrm{NPC}^{*}$, where $p_{1}+\ldots+p_{n}$ are deontic prescriptions derived from the set of racist practices, $d_{1}+\ldots+d_{n}$ are the negative properties derived from the racist ideology, and $\mathrm{NPC}^{*}$ is the semantic value of the appropriate non-pejorative correlate of the epithet.

What should these properties $p_{1}, \ldots p_{n}$ be in the case of dyke?

The first point to make is that the stereotypes associated with the term $d y k e$ are extremely 
dependent on the context and the community of practice in which the word is being used (see also McConnell-Ginet, 2002, Jones, 2012, among others). Surveying the anthropological and sociolinguistic literatures on lesbian identities in the US and in the UK, we find that a number of properties are frequently mentioned in connection with the term dyke (Davis and Kennedy, 1993; Halberstam, 1998; Koller, 2008; Burgess, 2011; Jones, 2012; Wiedlack, 2015; Ainley, 2016, among many others). These include:

Properties commonly stereotypically associated with dykes

1.Engagement in stereotypically masculine practices, including aspects of appearance (short hair, boots), masculine activities/professions, particularly working class ones, etc.

2.Overt sexual desire for women.

3.Radical, anti-mainstream or counter culture stance 9

Based on the literature, there seems to be variation in whether the properties in (15) cluster together for speakers across communities, and, correspondingly, whether or not $d y k e$ is associated with all of them. For example, communities where masculine practices, overt sexuality and anti-mainstream stances go together and are associated with the term dyke are those participating in the queercore/dykecore (queer feminist punk) movement: a musical, artistic and political movement exploring issues related to gender and sexuality within punk (see Wiedlack, 2015, Nault, 2017, for recent histories). Many artists and participants in this movement self-identify/ied as dykes, and craft(ed) artistic personae that valorize gender transgressive and anti-mainstream behavior. For example, describing one of the most influential dykecore groups, Tribe 8, lead singer Lynn Breedlove says that they are "San Francisco's own all-dyke, all-out, in-your-face, blade-brandishing, gang castrating, dildo swingin', bullshit-detecting, aurally pornographic, neanderthal-pervert band of patriarchy-smashing snatchlickers" (cited in Wiedlack, 2015, 39), a description that references a variety of masculine, overtly sexual and anti-social practices. Similarly, Figure 4 shows the cover of a dykecore zine linking dyke (in both of Canada's official languages) to working class masculine appearance and radical politics, through the image of work boots smashing flawless ice.

However, female masculinity, overt sexuality and radical politics are not so linked in other communities, and they are not all associated with the term dyke across spatio-temporal contexts (see also Koller, 2008; Jones, 2012). For instance, in her sociological study of participants of the Toronto Dyke March, Burgess (2011) asked her interviewees to discuss the differences between the words lesbian and dyke. In their answers, participants referenced only two of the properties in (15); anti-sociality and masculinity. Burgess reports (p.172-3)

\footnotetext{
${ }^{9}$ These three properties are most likely related: as discussed in Kiesling (2009), masculinity in the US/UK is hegemonically linked to hetereosexuality; therefore, point 2. could be viewed as actually an instance of point 1. Additionally, engagement in stereotypically masculine practices by people with female bodies is generally not supported by mainstream social institutions (see Eckert and McConnell-Ginet, 2013 , for discussion), so point 3 . could be though of as a consequence of points 1-2.
} 


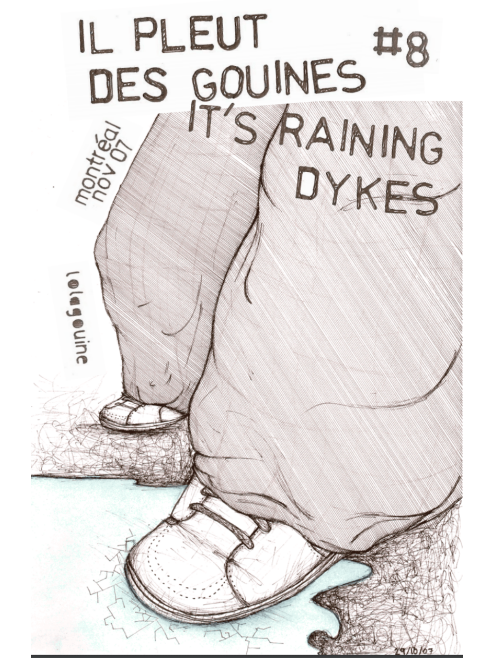

Figure 4 - Cover of Queer Zine from Montréal (2007) (Qzap archive http://archive .qzap. org/index.php/Detail/Object/Show/object_id/338)

that the anti-mainstream aspects of $d y k e$ were very salient to both participants and nonparticipants of the Dyke March, and that "the tension in the name was highlighted by the fact that groups of women who did not identify as dykes but as lesbian or gay were not participating in the March because of a perception that the March was "too radical" for them". She quotes Chris Renna (the Dyke March coordinator) describing other mainstream oriented lesbians who avoided the March saying (p.172), "She had friends who didn't come out to march because [...] it was too radical for them. That it wasn't a space for them because they're sort of like, you know, middle-class people who are professionals and have a dog and a condo and they don't feel like that space is for them." Burgess also reports (p.167) that masculinity plays a large role in determining who is a dyke, but only for older women. Thus, ideological representations associated with dyke can vary even within a single community of practice.

With this in mind, applying Hom's stereotype analysis to dyke would yield something like (16), and the properties in this definition, which may be variable within and across communities, provide a natural source for the scalar use of the term.

(16) Dyke means: "Ought to be subject to [insert various oppressions here] because of (for example) having a masculine appearance, being working class, having sexual desire for women, being anti-mainstream etc., all because of being a lesbian."

As shown in (16), Hom's stereotype analysis proposes that the stereotypical properties of dykes arise "all because of being a lesbian". Indeed, it is very common to assume that the meaning of the slur is defined in terms of the meaning of a "neutral" term (see also Potts, 2005; Schlenker, 2007; Camp, 2013; Jeshion, 2013a, among many others). But now 
we must ask: what does it mean to be a lesbian?

It turns out that this is not a trivial question. Indeed, as discussed by (McConnell-Ginet, 2002, 246), "although the choice between gay and homosexual certainly has political overtones, neither of those words has been the site of as much ideological struggle as lesbian, with its connections not only to antihomophobic but also to antisexist politics", and "there have been many disputes on just what being lesbian might amount to." At the heart of these disputes is the fact that very many communities of non-heterosexual women are deeply divided along three main lines outlined in (17) (Davis and Kennedy, 1993; Halberstam, 1998; Cameron and Kulick, 2003; McConnell-Ginet, 2002; Wiedlack, 2015):

\section{Some political and ideological conflicts in lesbian communities}

1. How they feel about female masculinity.

2. What role same gender sexual desire plays in non-heterosexual identity.

3. How well integrated into the mainstream "neoliberal consumer and heteronormative cultures" (Wiedlack, 2015, 17) non-heterosexual people should be.

These conflicts became fully developed with the rise of the lesbian feminist political movement, which was very influential in the 1980s and early 1990s. This movement deemphasized the importance of sexual desire for lesbian identity (Rich, 1980; Faderman, 1981; Wittig, 1992): it "privileged passionate and loving relationships over specifically sexual relationships in defining lesbianism" (Davis and Kennedy, 1993, 12), and works such as Faderman (1981) "emphasize[] the historical continuity of women's passionate friendships in the middle and upper classes throughout history" (Davis and Kennedy, 1993, 11). Many lesbian feminists were extremely critical of female masculinity (butch identities, drag kings, etc.), and were politically active for the integration of non-heterosexual women into mainstream institutions (marriage, family, legacy etc.) (Davis and Kennedy, 1993; Halberstam, 1998; Wiedlack, 2015).

Thus, since the 1980s we see develop (at least) two identities, or what, following work in sociolinguistics (Zhang, 2005; Podesva, 2007; Eckert, 2008), I will call personae for nonheterosexual women: what I will call the mainstream persona and the anti-mainstream persona. The mainstream persona has a stereotypically feminine appearance and engages in stereotypically feminine practices, is ambiguous with respect to same-sex desire, and is (upper) middle class. Furthermore, she has a pro-mainstream stance, looking for advancement within the existing heteronormative, capitalist system 10 . The anti-mainstream persona has stereotypically masculine appearances and practices, expresses overtly same gender desire, is working class, has a radical anti-system stance 11 .

\footnotetext{
${ }^{10}$ Particularly salient examples in fiction of the mainstream persona would be Bette and Tina on the $L$ Word.

${ }^{11}$ Particularly salient examples of the anti-mainstream persona are the stage personae of Lynn Breedlove from Tribe 8 and Donna Dresch from Team Dresch.
} 
Clearly, there is a connection between the properties that speakers associate with the term dyke and the dimensions of conflict in (17): dykes lie at the extreme end of each scale. In the next section, I will present my analysis of the meanings of dyke and lesbian that makes this connection explicit.

\section{A persona-based semantics in conceptual spaces}

This section presents a new semantics ${ }^{12}$ for both dyke and lesbian set within Gärdenfors (2000, 2014)'s conceptual spaces framework for lexical semantics. In this approach, speaker and listener conceptual and ideological structures are represented as a tuple $\langle D$, sim, PERS, $\mu\rangle$, where $\langle D$, sim $\rangle$ is an $|D|$-dimensional vector space with a relation sim measuring distance between points, and PERS is a distinguished set of points representing the locations of personae in the ideological space ${ }^{13}$. In addition to their properties, many theories of stereotypes involve reference to their valence: whether speakers/listeners are positively or negatively disposed towards them (Greenwald et al., 2002). $\mu$ is a function encoding these dispositions which partitions PERS into positively valued personae and negatively valued personat 14 .

In addition to varying across communities, it is possible that both the set of personae and valence are context sensitive. For some conceptual domains, it has been shown that the set of dimensions and personae can be empirically inferred from experimental data (see, for example, Douven, 2016), and an exciting area for future research would be to see how/whether the spaces into which lesbian, dyke and other related terms are interpreted can be constructed from empirical data gathered in (non)lesbian communities of practice. However, in this paper, I will simply assume that we are working with a simple space composed of the three dimensions in (18), based on (17), and suppose that valence is relatively consistent across contexts.

$$
\begin{aligned}
& \text { a. Masculinity (masculine } \leftrightarrow \text { feminine) } \\
& \text { b. Same gender sexual desire (more desire } \leftrightarrow \text { less desire) } \\
& \text { c. } \quad \text { Radical stance (anti-mainstream } \leftrightarrow \text { mainstream) }
\end{aligned}
$$

\footnotetext{
${ }^{12}$ There are obvious similarities between my use of Conceptual Spaces and Camp (2013)'s perspectives approach in which slurs are proposed to communicate perspectives: " modes of interpretation: open-ended ways of thinking, feeling, and more generally engaging with the world and certain parts thereof (Camp 2006, 2008, 2009)" (Camp, 2013, 333-334). In this paper, Camp (p.344) leaves "the question of what particular semantic status to assign perspectives for another day." Therefore, I think that one way of viewing my proposal is as providing a more explicit grounding for Camp's perspectives.

${ }^{13}$ Readers familiar with Gärdenfors' framework will recognize that my personae play the role of his prototypes.

${ }^{14} \mu$ could certainly have more structure to it but a simple positive/negative distinction will be sufficient for the illustration here.
} 
With this simple framework, we can already represent a number of ideologies associated with non-heterosexual women. For example, Figure 5 represents a possible lesbian feminist ideology. There are two personae: a mainstream persona, which is very low on the antimainstream and masculinity dimensions while being ambivalent with respect to sexual desire. This mainstream persona is positively valued, where positive valence is marked with o. There is also an anti-mainstream persona, which lies very high on all three dimensions, and which is negatively valued (marked by $\mathbf{x}$ ). Figure 5 also shows an example of a queer feminist punk ideology, of the kind espoused by Tribe 8 or Team Dretsch: there are the mainstream and anti-mainstream personae; however, in contrast to the lesbian feminist in Figure 5, the anti-mainstream persona is the one that is positively valued.
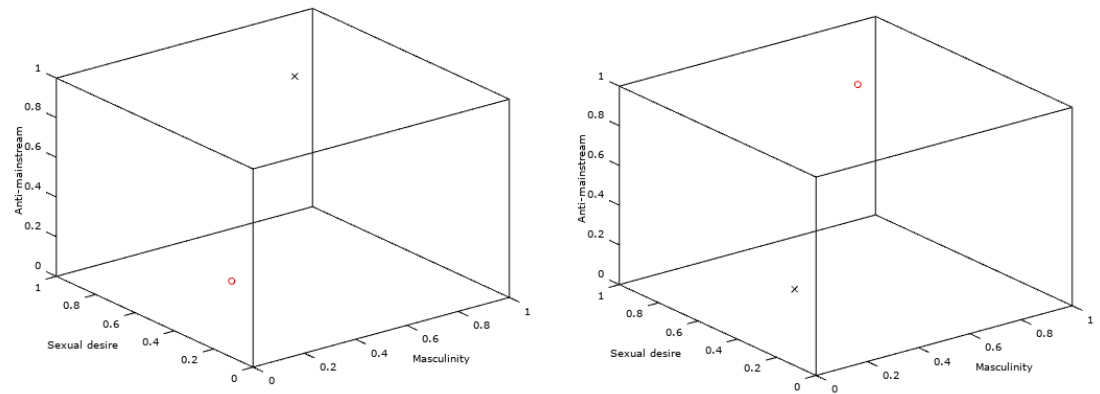

Figure 5 - Examples of lesbian feminist (left) and feminist punk (right) ideologies

Finally, we can also consider another ideology, a more 'traditional' or 'bigot' ideology, such as the one shown in Figure 6. This ideology is degenerate in both the social and the mathematical sense of the word, and it contains only the anti-mainstream persona which is negatively valued.

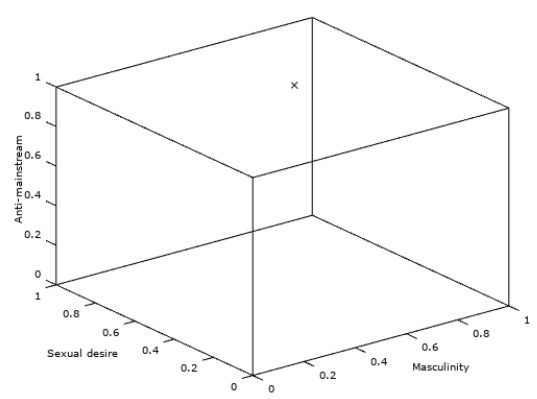

Figure 6 - Example of a bigot ideology

In this framework, expressions like lesbian or dyke are associated with personae, and the arrangement of personae in the space imposes constraints on the denotations of these expressions, which are regions in the space. As discussed by Gärdenfors and Jäger (2007); Jäger and Van Rooij (2007), given an n-dimensional conceptual space and a distinguished set of points, there is a natural way of partitioning this space into discrete regions: voronoi polygons. The voronoi polygon associated with a persona $p_{i}, v\left(p_{i}\right)$, is the set of points 
that lie closer to $p_{i}$ than to any other persona in the domain (19-a). The Voronoi tesselation generated by a set of personae PERS, V(PERS), is the collection of voronoi polygons associated with every persona in PERS (19-b).

(19) Let $p_{i} \in$ PERS be a persona.

$$
\begin{array}{ll}
\text { a. } & v\left(p_{i}\right):=\left\{x \mid \forall j\left(\operatorname{sim}\left(x, p_{i}\right) \leq \operatorname{sim}\left(x, p_{j}\right)\right)\right\} \\
\text { b. } & V(\mathrm{PERS}):=\left\{v\left(p_{i}\right) \mid p_{i} \in \mathrm{PERS}\right\}
\end{array}
$$

For both the lesbian feminist and the queer feminist punk, the space is partitioned between the anti-mainstream and mainstream personae. However, for the bigot, there is a single cell occupying all the space. Unsurprisingly, I will propose that dyke denotes the voronoi polygon associated with the anti-mainstream persona for all kinds of speakers/listeners. For lesbian, things are a bit more complicated. The bigot's ideological structure constrains the interpretation of lesbian to the polygon associated with the anti-mainstream persona. Thus, we predict that, for speakers with this ideology, lesbian and dyke should be synonymous (20). Indeed, the title of the wildly successful TV show The L-Word, about lesbians in Los Angeles, highlights how at least a certain portion of the population finds lesbian to be so vulgar it needs to be euphamized. Likewise, in February 2018, Republican candidate Leslie Gibson used the phrase "skinhead lesbian" to denigrate Emma Gonzales, a Parkland School Shooting survivor and anti-gun activist, and Gibson ended up apologizing not for being mistaken about Gonzales' sexual orientation, but for the fact that his comments were "harsh and uncivil"15.

$$
\begin{aligned}
& \text { Bigot interpretation schema } \\
& \text { a. } \llbracket \text { dyke } \rrbracket=v\left(\mathbf{x}_{(0.7,0.7,0.9)}\right) \\
& \text { b. } \llbracket \text { lesbian } \rrbracket=v\left(\mathbf{x}_{(0.7,0.7,0.9)}\right)
\end{aligned}
$$

For speakers that have more developed ideologies about non-heterosexual women ${ }^{16}$, more options are possible. Again, there could be variation across communities, but, at least in the ones I am most familiar with, lesbian is associated with both personae, and so its denotation is composed of the union of the polygons associated with the (anti)mainstream personae (21) and (21).

(21) Lesbian feminist interpretation schema

$$
\begin{array}{ll}
\text { a. } & \llbracket \text { dyke } \rrbracket=v\left(\mathbf{x}_{(0.7,0.7,0.9)}\right) \\
\text { b. } & \text { lesbian } \rrbracket=v\left(o_{(0.3,0.5,0.1)}\right) \cup v\left(\mathbf{x}_{(0.7,0.7,0.9)}\right)
\end{array}
$$

\footnotetext{
15 https://www.nytimes.com/2018/03/18/us/politics/maine-republican-leslie-gibson.html

${ }^{16}$ In this paper, we limit ourselves to representing ideologies of the domain of words for (for lack of a better term) "non-heterosexual women". But what are shown here are simply small corners of larger ideologies associated with personae in society.
} 
Queer punk interpretation schema
a. $\quad \llbracket$ dyke $\rrbracket=v\left(o_{(0.7,0.7,0.9)}\right)$
b. $\llbracket$ lesbian $\rrbracket=v\left(\mathbf{x}_{(0.3,0.5,0.1)}\right) \cup v\left(o_{(0.7,0.7,0.9)}\right)$

Arguments for including the region defined by the anti-mainstream persona into the denotation of lesbian comes from the observation that dykes and dyke-related things are generally considered also to be lesbians and lesbian-related things. For example, the set of dyke haircuts depicted in the punk zine shown in Figure 7 are a proper subset of the lesbian haircuts described on the pro-mainstream website After Ellen ${ }^{17}$.

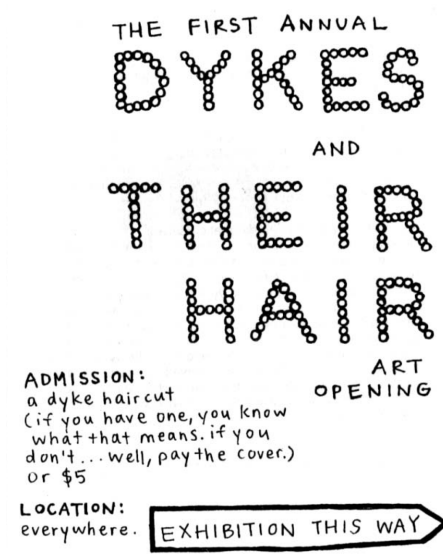

Figure 7 - 2008 Dykecore zine (Peterborough, Ontario) http://archive.qzap.org/index . php/Detail/Object/Show/object_id/173

In a conceptual spaces model, the function of a noun such as dyke or lesbian is to allow the speaker to communicate the location of the referent of the noun to the listener. Following (Jäger, 2007; Jäger and Van Rooij, 2007; Warglien and Gärdenfors, 2013; Gärdenfors, 2014; Burnett and Bonami, 2019), communication using conceptual spaces can be described as a game: the speaker knows the location of a particular individual, call them $x$, in their ideological structure, and they wish to communicate this information to the listener. In order to do so, the speaker chooses a message (word or phrase) to say to signal $x$ 's location to the listener. The listener hears the speaker's message and then places $x$ in some location in their own ideological structure. In the case where both the speaker and the listener have the same ideological structures and their interests are aligned, success for both players decreases as the distance between $x$ 's location in the speaker's ideology and $x$ 's location in the listener's ideology increases.

In order to pick the optimal word to say to communicate $x$ 's location, the speaker must make hypotheses concerning what their interlocutor's ideological structure looks like. Likewise, in order to interpret the speaker's message, the listener must make a hypothesis about their interlocutor's ideological structure. Upon hearing the message, the listener calculates

17 http://www.afterellen.com/people/448587-lesbian-haircut-guide 
a new location for $x$ in their own ideology, by taking into account the closest personae associated with the message, their prior beliefs and considerations such as Gricean informativity 18 .

This analysis makes an important prediction concerning the use and interpretation of lesbian and dyke: since the meaning of dyke is a subset of the meaning of lesbian, the former term is more informative than the latter for communicating that $x$ lies within the polygon associated with the anti-mainstream persona. Thus, we predict that, for speakers whose ideologies distinguish mainstream and anti-mainstream personae (such as both the lesbian feminist and the feminist punk), dyke and lesbian will not be truth conditionally equivalent, with dyke being used to "push" $x$ closer to the domain of the anti-mainstream persona in the discourse context and lesbian being used to "push" $x$ in the direction of the mainstream persona.

I argue that these predictions are borne out: we find many examples of instances where individuals claiming the identity of lesbian make distinctions between themselves an other non-heterosexual women who they believe fall in the category of dykes (see also Livia, 2002; Crémieux, 2013). An example of this from DTWF is shown in Figure 8, where the woman writing in the personal ad, a financially stable capitalist, is looking for a girlfriend, but does not want to date dykes.

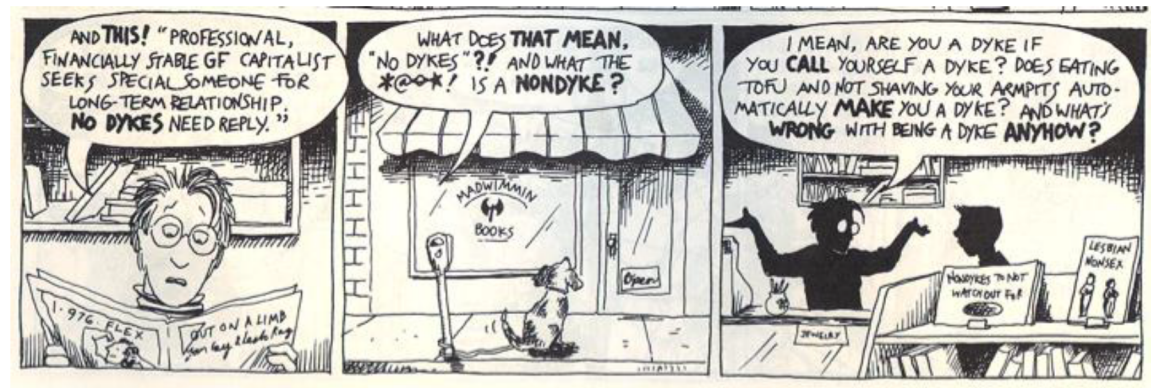

Figure 8 - DTWF \#82 (1990), reproduced from Crémieux (2013).

The non-truth conditional equivalence between lesbian and dyke (in non-bigot ideologies) becomes even clearer in the interpretation of comparatives. In 2012, Autostraddle, a mainstream lesbian/queer blog, published their list of the "21 most lesbianish cities in the US", based on a combination of very mainstream properties: lesbian population, resources, stateprovided marriage/anti-discrimination rights, political climate etc. Using this mainstream metric, Amherst/Northampton was ranked first, Los Angeles was ranked third and San Francisco (one of the homes of the dykecore movement) was ranked fourth. Given this, it is clear (to me) that while the comparative in (23-a) is true, (23-b) is false. Rather it is (23-c) that is true.

\footnotetext{
${ }^{18}$ This process is formalized in the context of personae and ideological spaces, using the Rational Speech Act model (Frank and Goodman, 2012), in Burnett and Bonami (2019).
} 

a. Los Angeles is more lesbianish than San Francisco.
b. Los Angeles is more dykeish than San Francisco.
c. San Francisco is more dykeish than Los Angeles.

The use of variation between dyke and lesbian to present referents in different (anti)mainstream oriented lights can be seen in examples such as Figure 9. In this strip, Mo is expressing her incredulity to Lois that lesbians would participate in something that is so far away from commonly accepted female sexual practices. Lois, who is enthusiastic about anonymous sex, assures her that the club will be packed with dykes.
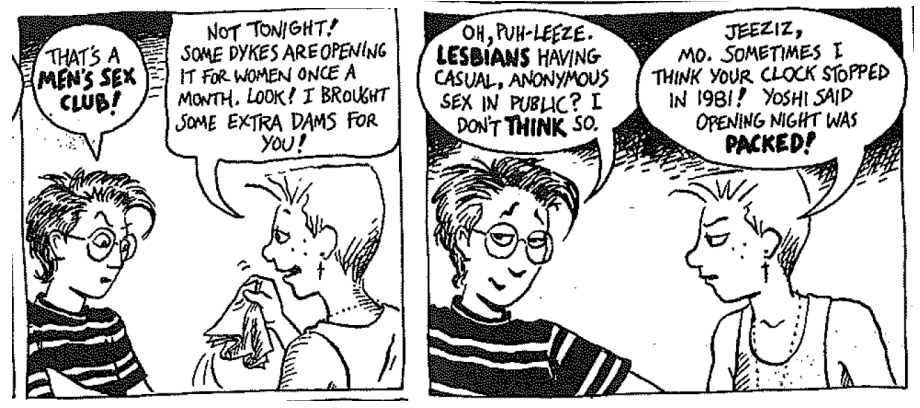

Figure 9 - DTWOF \#144 (1992)

To investigate whether the pattern in Figure 9 was general, I did a small corpus study of dyke vs lesbian variation in the comic strip Dykes to Watch Out For (340 comics over the years 1987-2000). The three dimensions of ideological conflict described in (17) are all active in the DTWF world. For example, as shown in Figure 10, Sparrow objects to Lois' participation in a drag king contest, suggesting that these two characters have opposite views on female masculinity.

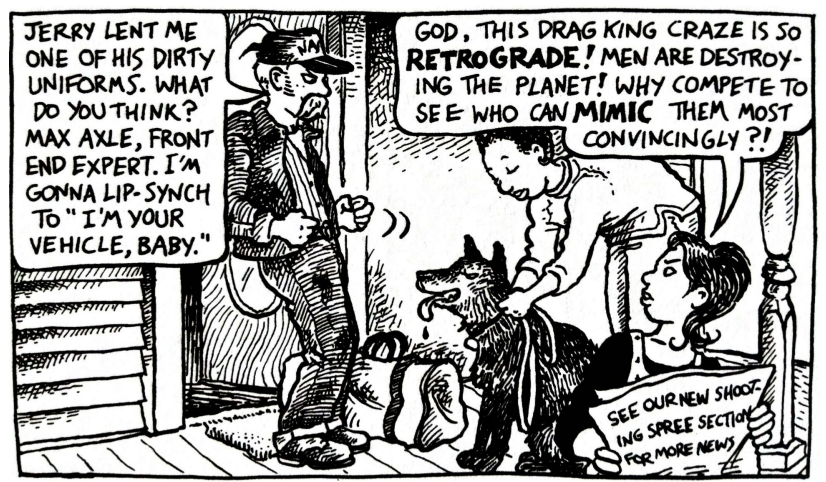

Figure 10 - Dykes to Watch Out For \#325 (1999)

Sparrow also appears to place more importance on lifestyle aspects of being a lesbian than overt, exclusive same gender sexual attraction, as shown in Figure 11, something that other characters, such as Ginger, find confusing. 

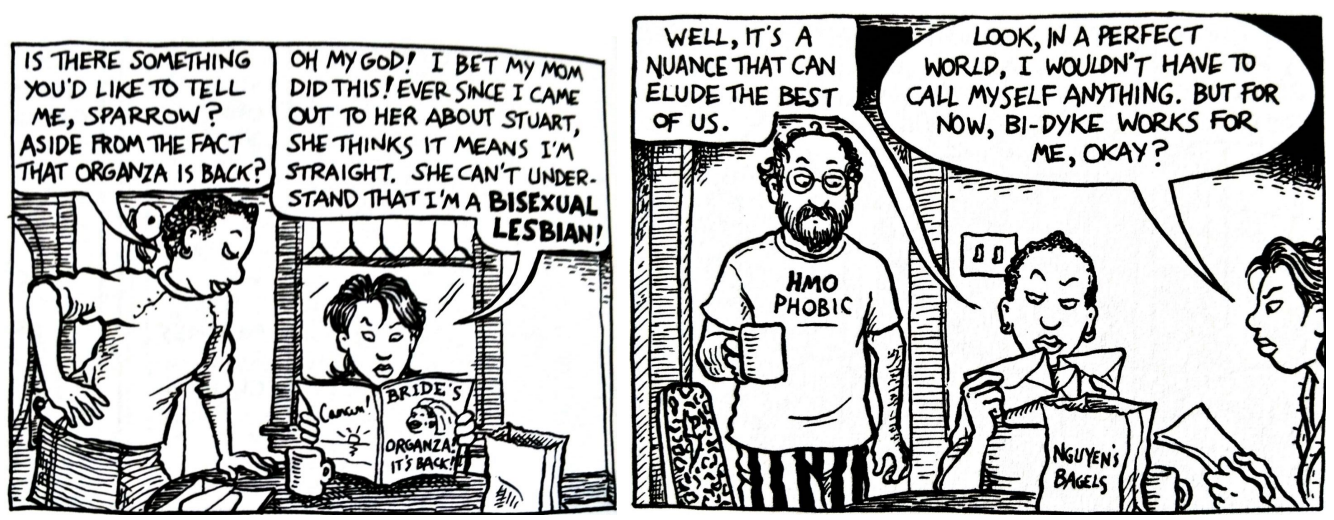

Figure 11 - Dykes to Watch Out For \#323 (1999)

Finally, Figure 12 exemplifies the more general political conflict that divides mainstream vs non-mainstream oriented lesbians: Tanya scolds Toni and Clarice at their commitment ceremony for engaging with "the imperialist patriarchy"; whereas, Jezanna views this move as a groundbreaking step towards legitimizing lesbian relationships.
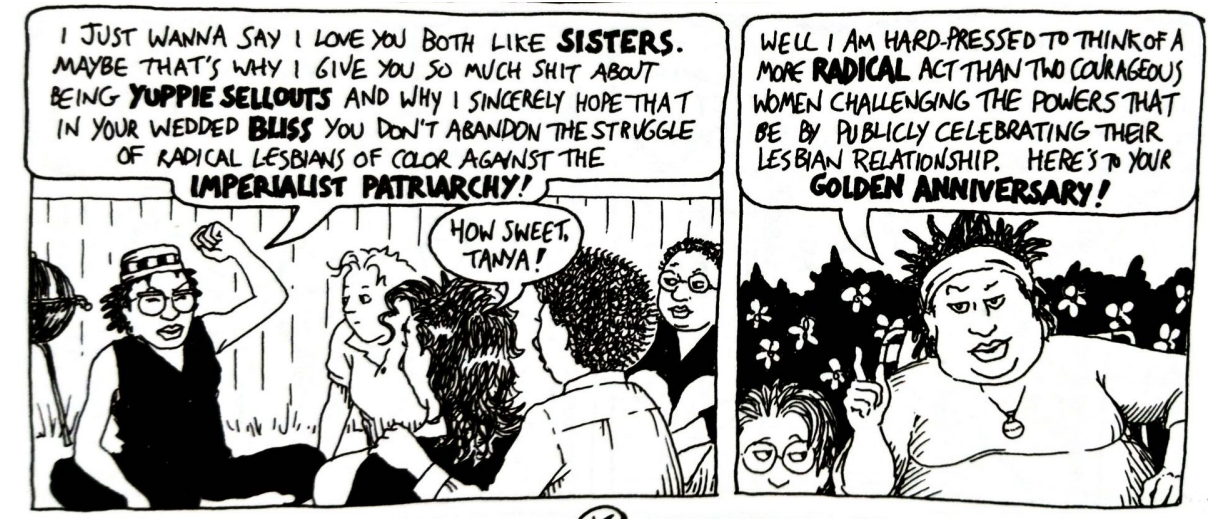

Figure 12 - Dykes to Watch Out For \#87 (1990)

Table 11 shows the distribution of the use of dyke vs lesbian in the first 340 comics of Dykes to Watch Out For according to their their context of use; that is, I coded each example for whether it appeared in a context related to domesticity (children, families), politics/political activism, criticizing mainstream institutions (marriage, heterosexuality, capitalism), sex or to something else. Sadly, there are only 104 occurrences in this corpus 19 , nevertheless, a clear pattern emerges: although lesbian is used across all contexts, contexts in which individuals are acting in ways associated with the anti-mainstream persona have higher rates of $d y k e$, as predicted by the conceptual spaces analysis.

\footnotetext{
${ }^{19}$ After all, how often do we utter identity terms in everyday interactions?
} 


\begin{tabular}{|l|c|c|c|}
\hline Discourse context & dyke & lesbian & $\%$ dyke \\
\hline Political & 2 & 37 & $5 \%$ \\
Domestic & 2 & 21 & $9 \%$ \\
Other & 2 & 11 & $15 \%$ \\
Sex & 9 & 13 & $40 \%$ \\
Anti-mainstream & 4 & 3 & $57 \%$ \\
\hline Total & 19 & 85 & $18 \%$ \\
\hline
\end{tabular}

Table 1 - Lesbian vs dyke by context in DTWF (1987-2000).

\section{Conclusion}

This paper gave an in depth study of a "classic" example of a slur (dyke) and its "neutral" sister (lesbian). I argued that current approaches to the formal semantics of slurs, such as expressivism, the deflationary theory and some stereotype approaches, either make incorrect predictions or are incomplete when applied to uses of dyke and lesbian by both 'in group' and 'out group' members. I presented a new analysis in which neither dyke nor lesbian are politically neutral; rather they are associated with different sets of personae: discursively constructed mental objects that impose constraints on the meaning of identity terms. I have argued that this approach is appropriate for dyke/lesbian, and I leave open the possibility that it may be helpful in understanding the complex semantic, pragmatic and social behaviour of the wide range of linguistic expressions that have been analyzed under the umbrella of the term "slur". Examples that, at least at first glance, lend themselves well to the anti-mainstream persona-style treatment are other slurs related to sexual identity, such as fag (Pascoe, 2011) and slut (Armstrong et al., 2014).

My analysis solves the formal semantic puzzles described in section 2 through the interaction between the meaning of the dyke in the listener's own ideology and their hypotheses about what the speaker's underlying ideological structure looks like, given that they uttered a slur term. Since the semantic meaning of dyke is defined by an anti-mainstream persona, one which is assigned negative valence by most members of society, in most discourse situations, the listener will (accurately) infer that the speaker holds a derogatory attitude to the slur's target. The inference that the speaker holds a negative attitude towards the persona associated with dyke is an inference about ideological structure, not semantic meaning; therefore, if the listener draws this inference in assertions containing the slur, we predict they will also draw it in all other semantic environments. Thus, the derogatory attitude will be unpluggable. If there is common knowledge between the speaker and listener that the speaker has/is having an ideology in which the anti-mainstream persona is viewed positively, then (and only then) will the derogatory attitude inference have no chance of being drawn. Thus, in these very limited circumstances, we can have appropriation. However, the only ideologies in which the anti-mainstream persona is viewed positively are those similar to the feminist punk ideology, and these views have a very restricted distribution in society. As discussed above, most people, including some lesbians, 
do not have a feminist punk-like perspective. Therefore, people wishing to use dyke without offending their interlocutor should be very careful, since common knowledge of positive valence is very rare. If the common knowledge condition is not met, they risk offending their interlocutor even if this is not their intention.

The account that I have provided in this paper is based on the idea that we all bring ideological structure to our linguistic interactions and that we reason about speaker meaning based on our hypotheses about others' ideologies. But how do these mental representations and reasoning processes translate into the real world oppression that slurs reinforce and promote? I suggest that the answer to this question lies in the inequality between the social contexts in which the mainstream persona is positively valued and the contexts in which the anti-mainstream persona is positively valued. Although there are certainly some situations where being viewed as a dyke is advantageous ${ }^{20}$, when interacting with the institutions that control resources like housing, employment opportunities and immigration options, it generally pays to be viewed as more mainstream. Mainstream institutions support mainstream individuals and often deny protection and access to their resources to those that deviate from the "proper" path. Thus mentally situating someone outside the mainstream, and encouraging others to do likewise, can have serious consequences for their well-being and the life that they are forced to live.

\section{References}

Ainley, R. (2016). What is She Like: Lesbian Identities from the 1950 s to the 1990 s. Bloomsbury Publishing.

Anderson, L. (2018). Calling, addressing, and appropriation. Bad Words.

Anderson, L. and Lepore, E. (2013a). Slurring words. Noûs, 47(1):25-48.

Anderson, L. and Lepore, E. (2013b). What did you call me? slurs as prohibited words. Analytic Philosophy, 54(3):350-363.

Armstrong, E. A., Hamilton, L. T., Armstrong, E. M., and Seeley, J. L. (2014). ?good girls? gender, social class, and slut discourse on campus. Social Psychology Quarterly, $77(2): 100-122$.

Baugh, J. (1983). Black street speech: Its history. Structure, and Survival. Austin.

Bechdel, A. (2008). The Essential Dykes To Watch Out For. Houghton Mifflin, Boston.

Bianchi, C. (2014). Slurs and appropriation: An echoic account. Journal of Pragmatics, $66: 35-44$.

Bolinger, R. J. (2017). The pragmatics of slurs. Nô̂s, 51(3):439-462.

\footnotetext{
${ }^{20}$ Burgess (2011)'s description of the discomfort of some mainstream lesbians at the Dyke March gives an example of such a situation.
} 
Burgess, A. H. (2011). It's Not A Parade, It's A March!: Subjectivities, Spectatorship, and Contested Spaces of the Toronto Dyke March. PhD thesis, University of Toronto.

Burnett, H. and Bonami, O. (2019). A conceptual spaces model for socially conditioned language change. In Pater, J. and Garoz, G., editors, Proceedings of the Society for Computation in Linguistics, volume 2. SCIL.

Cameron, D. and Kulick, D. (2003). Language and sexuality. Cambridge University Press.

Camp, E. (2013). Slurring perspectives. Analytic Philosophy, 54(3):330-349.

Cepollaro, B. (2017). The Semantics and Pragmatics of slurs and thick terms. PhD thesis, PSL Research University.

Crémieux, A. (2013). Rich dykes from LA are called lesbians. TV/Series, 4.

Croom, A. M. (2011). Slurs. Language Sciences, 33(3):343-358.

Croom, A. M. (2013). How to do things with slurs: Studies in the way of derogatory words. Language \& Communication, 33(3):177-204.

Davis, M. and Kennedy, E. L. (1993). Boots of leather, slippers of gold: The history of a lesbian community. New York: Roudedge.

Douven, I. (2016). Vagueness, graded membership, and conceptual spaces. Cognition, 151:80-95.

Eckert, P. (2008). Variation and the indexical field. Journal of sociolinguistics, 12(4):453476.

Eckert, P. and McConnell-Ginet, S. (2013). Language and gender. Cambridge University Press.

Faderman, L. (1981). Surpassing the love of men: Romantic friendship and love between women from the Renaissance to the present. Morrow New York.

Frank, M. C. and Goodman, N. D. (2012). Predicting pragmatic reasoning in language games. Science, 336(6084):998-998.

Gärdenfors, P. (2000). Conceptual spaces: The geometry of thought. MIT press.

Gärdenfors, P. (2014). The geometry of meaning: Semantics based on conceptual spaces. MIT Press.

Greenwald, A. G., Banaji, M. R., Rudman, L. A., Farnham, S. D., Nosek, B. A., and Mellott, D. S. (2002). A unified theory of implicit attitudes, stereotypes, self-esteem, and self-concept. Psychological review, 109(1):3.

Gutzmann, D. (2015). Use-conditional meaning: Studies in multidimensional semantics, volume 6. OUP Oxford.

Halberstam, J. (1998). Female masculinity. Duke University Press. 
Hedger, J. A. (2012). The semantics of racial slurs: using kaplan's framework to provide a theory of the meaning of derogatory epithets. Linguistic and Philosophical Investigations, $11: 74$.

Hom, C. (2008). The semantics of racial epithets. The Journal of Philosophy, 105(8):416440.

Hom, C. (2010). Pejoratives. Philosophy Compass, 5(2):164-185.

Hornsby, J. (2001). Meaning and uselessness: How to think about derogatory words. Midwest Studies in Philosophy, 25:128-141.

Jäger, G. (2007). The evolution of convex categories. Linguistics and Philosophy, 30(5):551564.

Jäger, G. and Van Rooij, R. (2007). Language structure: psychological and social constraints. Synthese, 159(1):99-130.

James, J. and Edwards, J. (2006). Falling off the edge of paradise. iUniverse.

Jeshion, R. (2013a). Expressivism and the offensiveness of slurs. Philosophical Perspectives, 27(1):231-259.

Jeshion, R. (2013b). Slurs and stereotypes. Analytic Philosophy, 54(3):314-329.

Jones, L. (2012). Dyke/girl: Language and identities in a lesbian group. Palgrave Macmillan.

Kaplan, D. (1999). The meaning of ouch and oops: Explorations in the theory of meaning as use. Manuscript, UCLA.

Kiesling, S. F. (2004). Dude. American speech, 79(3):281-305.

Kiesling, S. F. (2009). Style as stance. Stance: sociolinguistic perspectives, 171.

Koller, V. (2008). Lesbian discourses: Images of a community. Routledge.

Kratzer, A. (1999). Beyond "oops" and "ouch". how descriptive and expressive meaning interact. In Cornell Conference on Theories of Context Dependency, volume 26.

Labov, W. (1972). Sociolinguistic patterns. University of Pennsylvania Press.

Lakoff, R. (1973). Language and woman's place. Language in society, 2(1):45-79.

Livia, A. (2002). Camionneuses s'abstenir: Lesbian community creation through the personals. Language and sexuality: Contesting meaning in theory and practice, pages 191206.

McConnell-Ginet, S. (2002). Queering semantics: Definitional struggles. Language and sexuality: Contesting meaning in theory and practice, pages 137-60. 
McCready, E. S. (2010). Varieties of conventional implicature. Semantics and Pragmatics, $3: 8-1$.

Moonwomon-Baird, B. (1997 [1985]). Toward a study of lesbian speech. Queerly phrased, pages 202-213.

Nault, C. (2017). Queercore: Queer Punk Media Subculture. Routledge.

Pascoe, C. J. (2011). Dude, you're a fag: Masculinity and sexuality in high school. Univ of California Press.

Podesva, R. (2007). Phonation type as a stylistic variable: The use of falsetto in constructing a persona. Journal of sociolinguistics, 11(4):478-504.

Potts, C. (2005). The logic of conventional implicatures. Oxford University Press, Oxford.

Potts, C. (2007). The expressive dimension. Theoretical linguistics, 33(2):165-198.

Potts, C. (2012). Conventional implicature and expressive content. Semantics: An international handbook of natural language meaning, 3:2516-2536.

Queen, R. M. (1997). Locating lesbian language. Queerly phrased: Language, gender, and sexuality, page 233 .

Rich, A. (1980). Compulsory heterosexuality and lesbian existence. Signs: Journal of women in culture and society, 5(4):631-660.

Richard, M. (2008). When Truth Gives Out. Oxford University Press, New York.

Ritchie, K. (2017). Social identity, indexicality, and the appropriation of slurs. Croatian Journal of Philosophy, 17(2):155-180.

Ross, B. (2009). Burlesque west: Showgirls, sex, and sin in postwar Vancouver. University of Toronto Press.

Sauerland, U. (2007). Beyond unpluggability. Theoretical Linguistics, 33(2):231-236.

Schlenker, P. (2003). A plea for monsters. Linguistics and philosophy, 26(1):29-120.

Schlenker, P. (2007). Expressive presuppositions. Theoretical Linguistics, 33(2):237-245.

Smitherman, G. (2006). Word from the mother: Language and African Americans. Routledge.

Stanley, J. P. and Wolfe, S. J. (1980). The coming out stories. Watertown, MA: Persephone.

Taub, J. (1999). Bisexual women and beauty norms: A qualitative examination. Journal of Lesbian Studies, 3(4):27-36.

Tirrell, L. (1999). Derogatory terms: Racism, sexism and the inferential role theory of meaning. In Language and Liberation: Feminism, Philosophy and Politics. SUNY Press. 
Tirrell, L. (2012). Genocidal language games. Speech and harm: Controversies over free speech, pages 174-221.

von Fintel, K. (2004). Would you believe it? the king of France is back! presuppositions and truth-value intuitions. In Reimer, M. and Bezuidenhout, A., editors, Descriptions and Beyond, pages 269-296. Oxford University Press, Oxford.

Warglien, M. and Gärdenfors, P. (2013). Semantics, conceptual spaces, and the meeting of minds. Synthese, pages 1-29.

Wiedlack, M. K. (2015). Queer-Feminist Punk: An Anti-Social History. Zaglossus.

Wittig, M. (1992). The straight mind and other essays. Beacon Press.

Zhang, Q. (2005). A chinese yuppie in beijing: Phonological variation and the construction of a new professional identity. Language in society, 34(3):431-466. 